\title{
The effect of the Ontario Bariatric Network on health services utilization after bariatric surgery: a retrospective cohort study
}

\author{
Ahmad Elnahas MD MSc, Timothy D. Jackson MD MPH, Allan Okrainec MDCM MHPE, \\ Peter C. Austin PhD, Chaim M. Bell MD PhD, David R. Urbach MD MSc
}

\section{Abstract}

Background: In 2009, the Ontario Bariatric Network was established to address the exploding demand by Ontario residents for bariatric surgery services outside Canada. We compared the use of postoperative hospital services between out-of-country surgery recipients and patients within the Ontario Bariatric Network.

Methods: We conducted a population-based, comparative study using administrative data held at the Institute for Clinical Evaluative Sciences. We included Ontario residents who underwent bariatric surgery between 2007 and 2012 either outside the country or at one of the Ontario Bariatric Network's designated centres of excellence. The primary outcome was use of hospital services in Ontario within 1 year after surgery.

Results: A total of 4852 patients received bariatric surgery out of country, and 5179 patients underwent surgery through the Ontario Bariatric Network. After adjustment, surgery at a network centre was associated with a significantly lower utilization rate of postoperative hospital services than surgery out of country (rate ratio $0.90,95 \%$ confidence interval $[\mathrm{Cl}] 0.84$ to 0.97 ). No statistically significant differences were found with respect to time in critical care or mortality. However, the physician assessment and reoperation rates were significantly higher among patients who received surgery at a network centre than among those who had bariatric surgery out of country (rate ratio $4.10,95 \% \mathrm{Cl} 3.69$ to 4.56 , and rate ratio $1.84,95 \% \mathrm{Cl} 1.34$ to 2.53 , respectively).

Interpretation: The implementation of a comprehensive, multidisciplinary provincial program to replace outsourcing of bariatric surgical services was associated with less use of postoperative hospital services by Ontario residents undergoing bariatric surgery. Future research should include an economic evaluation to determine the costs and benefits of the Ontario Bariatric Network.

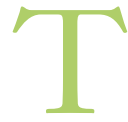

he demand for weight loss procedures has grown substantially in recent years. In 2009, $24 \%$ of Canadians were considered obese, up from just $6 \%$ in 1985. ${ }^{1}$ Nearly 6000 bariatric surgeries were carried out in Canadian hospitals in 2012/13, almost 4 times the number performed in 2006/07..$^{2}$ Before 2009, bariatric surgery was not widely available in Canada, despite its growing popularity worldwide. Canadian hospitals are typically funded by global budgets; clinical programs such as bariatric surgery, which require additional hospital resources such as new multidisciplinary teams of allied health professionals and purchase of capital equipment, rarely gain traction unless they are supported by incremental revenue streams. The average wait period for bariatric surgery in 2007 was just over 5 years, among the longest for any type of surgery in Canada. ${ }^{3}$ As a result, Canadians began turning to private centres offer- ing uninsured procedures or travelling out of country for treatment as medical tourists. ${ }^{4}$

Initially, the Ontario Ministry of Health and Long-Term Care, which funds health services in Ontario, denied coverage for out-of-country bariatric services because operations such as the Roux-en-Y gastric bypass and sleeve gastrectomy were insured, publicly available health services in Ontario. ${ }^{5}$ However, patients appealed successfully to the Ontario

\section{Competing interests: None declared.}

This article has been peer reviewed.

Correspondence to: David Urbach, david.urbach@wchospital.ca CMAJ Open 2016. DOI:10.9778/cmajo.20160042 
Health Services Appeal and Review Board, claiming that the long wait time for bariatric surgery made it functionally inaccessible. ${ }^{6}$ As a result, the Ontario Ministry of Health classified bariatric surgery as an eligible out-of-country health service in 2005 and referred Ontario residents to bariatric centres across the United States at their request. ${ }^{7}$ Within a few years, more than 1660 applications for out-ofcountry bariatric surgery were approved annually, at a cost of more than $\$ 50$ million. ${ }^{8}$ The increasing cost of these services and perceptions that follow-up care was poor prompted the Ministry of Health to create the Ontario Bariatric Network, a network of designated centres of excellence for bariatric surgery in Ontario, in 2009. ${ }^{8}$ Once the network was established, the province stopped outsourcing bariatric surgical services.

Before the implementation of the Ontario Bariatric Network, there was no provincially mandated standard for multidisciplinary care for patients undergoing bariatric surgery in Ontario and there was minimal surgical, medical, dietary or psychological supervision for Ontario residents who received bariatric surgery in the US. ${ }^{5}$ The lack of follow-up care could have delayed the diagnosis and treatment of postoperative complications, leading to unnecessary hospital admissions or emergency department visits. We sought to evaluate the impact of the program by comparing the use of postoperative hospital services between Ontario residents who received bariatric surgery at a network centre and those who received outof-country bariatric surgery.

\section{Methods}

\section{Study design and setting}

We conducted a retrospective cohort study using administrative data held at the Institute for Clinical Evaluative Sciences in Ontario, Canada. The study population consisted of Ontario residents who underwent bariatric surgery either outside Ontario (i.e., in the US) or through the Ontario Bariatric Network between Jan. 1, 2007, and July 31, 2012. We compared the use of postoperative health services at 1 year between the 2 groups.

The study protocol was approved by the Sunnybrook Health Sciences Centre Research Ethics Board, the University Health Network Research Ethics Board and the University of Toronto Office of Research Ethics.

\section{Data sources}

We obtained data from the Ministry of Health and LongTerm Care Out-of-Country Service Database on the type, date and location of surgery for all Ontario residents who received funded out-of-country bariatric surgery. The Ontario Health Insurance Plan database provided details on all claims paid to physicians during the study period, including claims for assessments, critical care services and operations. The Canadian Institute for Health Information (CIHI) Discharge Abstract Database contains information on the dates of hospital admissions and lengths of stay at acute care facilities in Ontario for all residents. We obtained information on emer- gency department visits from the CIHI National Ambulatory Care Reporting System database. The Ministry of Health's Registered Persons Database provided demographic and vital status information on holders of Ontario health cards.

\section{Implementation of the Ontario Bariatric Network}

The Ontario Bariatric Network was established on Apr. 1, 2009. The program has defined eligibility criteria for bariatric surgery and at the time of our study it centralized referrals to 1 of 4 provincial bariatric centres of excellence: St. Joseph's Healthcare Hamilton, the University of Toronto Collaborative Bariatric Surgery Program (Humber River Regional Hospital, St. Joseph's Health Centre, St. Michael's Hospital, Toronto East General Hospital, the University Health Network's Toronto Western Hospital, The Hospital for Sick Children), The Ottawa Hospital and Guelph General Hospital. Eligible patients are at least 18 years old with a body mass index greater than 40, or greater than 35 with at least 1 comorbidity responsive to weight loss. ${ }^{9}$ The program also has established surgical and perioperative care standards, including orientation and educational sessions, preoperative testing and formal anesthetic assessments. ${ }^{9}$ An assessment by an interdisciplinary bariatric team comprising a dietitian, social worker, registered nurse, psychologist, internist and surgeon is mandated to address the complex, multidisciplinary issues surrounding obesity and its comorbidities. ${ }^{4}$ All patients are required to follow up with the bariatric nurse practitioner at their centre following their surgery, and a physician assessment is conducted only if the nurse practitioner deems it necessary. Follow-up assessments are conducted at 1 month, 3 months, 6 months, 1 year and annually thereafter up to 5 years. ${ }^{9}$

\section{Patient selection}

We identified Ontario residents who received out-of-country surgery using the Ministry of Health's Out-of-Country Service Database, and we identified residents who received surgery through the Ontario Bariatric Network using specific bariatric surgery fee codes claimed at designated bariatric centres in Ontario. For patients with more than 1 bariatric procedure during the study period, we selected the first operation. We did not include patients who underwent private or uninsured bariatric procedures. The study follow-up period began on the patient's hospital discharge date for their principal operation. Discharge dates from hospitals in the US were not available in our database; therefore, we replaced date of discharge with date of surgery as the start of the follow-up period for patients treated out of country, given that Ontario health services use could occur only after a patient returned to Ontario. We set the end of the follow-up period as 1 year after the date of surgery to ensure that the duration of follow-up after surgery was equivalent for the 2 comparison groups (Figure 1).

\section{Outcome measures}

The primary outcome of our study was the number of days Ontario hospital services were used, which was a composite 
count of the number of emergency department visits and the total number of days admitted to hospital. Secondary outcomes included the number of days in a critical care unit and on ventilatory support, as measured using per diem physician fee codes. ${ }^{10}$ We identified all physician assessments using phy- sician billing codes. We identified postoperative reoperations using procedure fee codes for abscess drainage, bowel obstruction, bowel resection and feeding-tube placement. We also captured all-cause death within 30 days and 1 year after surgery to evaluate surgical outcomes.

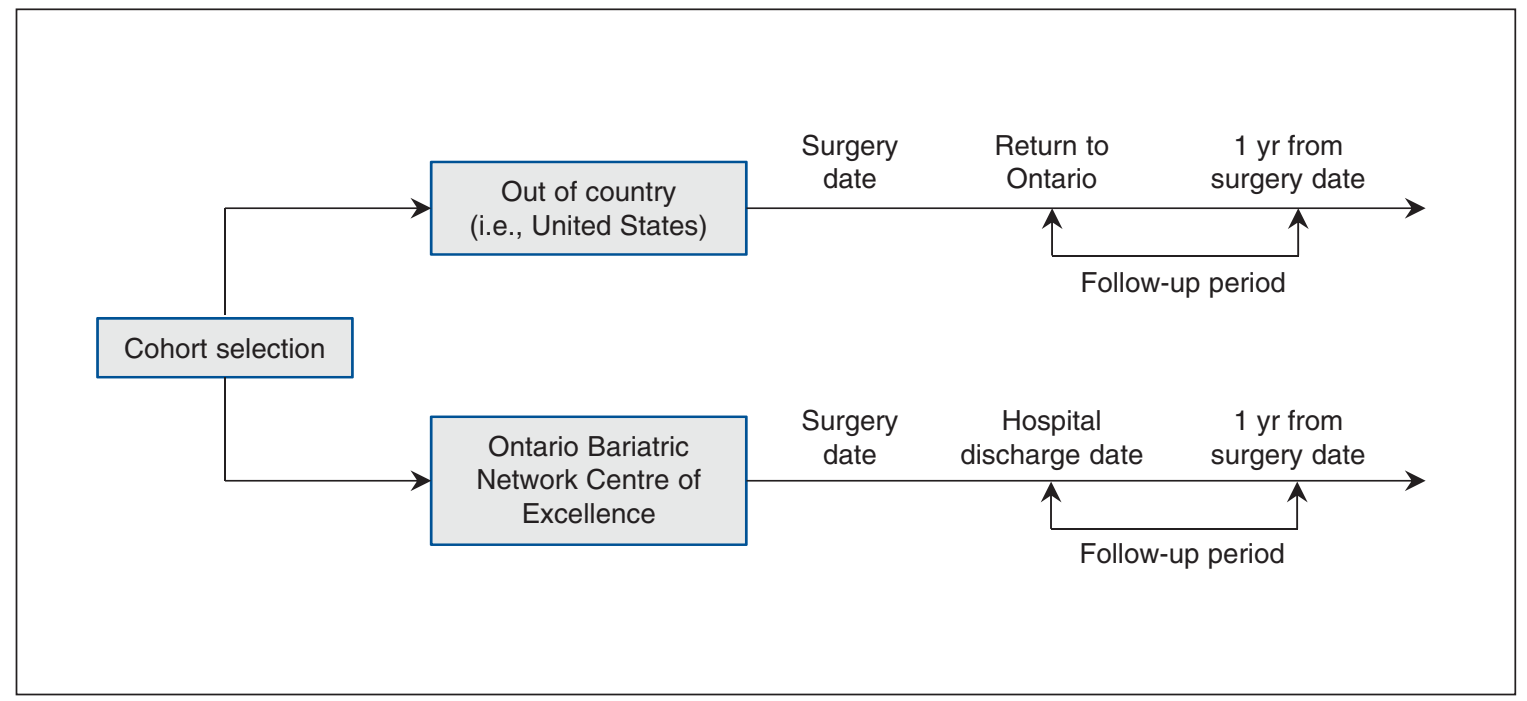

Figure 1: Study design and follow-up for cohorts.

Table 1: Characteristics of Ontario residents receiving bariatric surgery out of country and at an Ontario Bariatric Network centre of excellence, 2007-2012

\begin{tabular}{|c|c|c|c|}
\hline \multirow[b]{2}{*}{ Characteristic } & \multicolumn{2}{|c|}{ Group; no. (\%) or mean \pm SD } & \multirow[b]{2}{*}{ Difference* $(95 \% \mathrm{Cl})$} \\
\hline & $\begin{array}{l}\text { Out of country } \\
n=4852\end{array}$ & $\begin{array}{c}\text { OBN } \\
n=5179\end{array}$ & \\
\hline Age, yr & $43.7 \pm 10.3$ & $44.9 \pm 10.3$ & $1.3(0.9$ to 1.6$)$ \\
\hline Sex, female & $3868(80.5)$ & $4258(82.2)$ & $1.7(0.2$ to 3.3$)$ \\
\hline \multicolumn{2}{|l|}{ ACG comorbidity score } & & $p=0.3$ \\
\hline$\leq 2$ & $123(2.5)$ & $72(1.4)$ & \\
\hline 3 & $2844(58.6)$ & 3077 (59.4) & \\
\hline 4 & $1385(28.5)$ & $1524(29.4)$ & \\
\hline 5 & $500(10.3)$ & $506(9.8)$ & \\
\hline Rural residence $\dagger$ & $898(18.5)$ & $818(15.8)$ & $-2.7(-4.2$ to -1.2$)$ \\
\hline \multicolumn{2}{|l|}{ Neighbourhood income quintileł } & & $p=0.5$ \\
\hline 1 (lowest) & $1096(22.7)$ & $1169(22.6)$ & \\
\hline 2 & $1109(23.0)$ & 1201 (23.3) & \\
\hline 3 & $1005(20.8)$ & $1058(20.5)$ & \\
\hline 4 & $898(18.6)$ & $1008(19.5)$ & \\
\hline 5 (highest) & $718(14.9)$ & $728(14.1)$ & \\
\hline Procedure: gastric bypass & $4868(99.9)$ & $4738(91.5)$ & $-8.4(-7.6$ to -9.2$)$ \\
\hline $\begin{array}{l}\text { Note: ACG = Johns Hopkins Adjusted Clir } \\
{ }^{*} \text { Differences are reported as percentages } \\
p \text { values are reported. } \\
\text { tRural residence was defined as residen } \\
\text { flncome quintile was determined by linkir } \\
\text { Areas were then ranked and divided into }\end{array}$ & $\begin{array}{l}\text { ce interval, NS = not } \\
\text { where mean differe } \\
\text { population less than } \\
\text { to its corresponding } \\
\text { me quintile was code }\end{array}$ & $\begin{array}{l}\mathrm{BN}=\text { Ontario } \mathrm{B} \\
\text { ed. For comparis } \\
\text { area and then } \\
\text { e highest was co }\end{array}$ & $\begin{array}{l}\mathrm{D}=\text { standard deviation. } \\
\text { tics with more than } 2 \text { categories, } \\
\text { rage income per person in the area. }\end{array}$ \\
\hline
\end{tabular}




\section{OPEN}

Research

\section{Statistical analysis}

We compared baseline patient characteristics between the 2 cohorts using $t$ tests and $\chi^{2}$ tests as appropriate. We used negative binomial regression to estimate the effect of the program on the number of days health services were used after adjusting for potentially confounding variables. We also used logistic regression to estimate the effect of the program on 30-day and 1-year mortality. Models included the following independent variables: age, sex, household income quintile in neighbourhood of residence (an ecologic measure of socioeconomic status), rurality (rural v. urban residence), type of bariatric procedure (gastric bypass v. other) and the Johns Hopkins Adjusted Clinical Groups comorbidity score. ${ }^{11,12} \mathrm{We}$ chose all variables a priori on the basis of clinical relevance. We did not detect evidence of multicollinearity on the basis of a variance inflation factor threshold of $4 .{ }^{13}$ Although there were a high number of zero counts in our outcome data, the assumptions of model fit were satisfied using a conventional negative binomial regression model with no improvement in model fit using a zero-inflated negative binomial model. We present negative binomial regression results as rate ratios and logistic regression results as odds ratios with corresponding $95 \%$ confidence intervals (CIs). We considered $p$ values less than 0.05 to be statistically significant. We also did a subgroup analysis using only in-province hospitals outside the Ontario Bariatric Network to compare 1-year use of postoperative health services before and after 2010. We used SAS version 9.3 for UNIX (SAS Institute Inc.) to conduct our analyses.

\section{Results}

\section{Patient population}

A total of 4852 patients received bariatric surgery out of country and 5179 patients underwent surgery at an Ontario Bariatric Network centre of excellence. There were small but statistically significant differences in age, sex and rurality between the 2 groups (Table 1). The mean age was 44 years, with women making up about $81 \%$ of the patients. About $17 \%$ of patients lived in a rural location at the time of surgery, and the distribution of neighbourhood income quintiles was similar across the 2 groups. Almost all patients receiving out-of-country surgery underwent a gastric bypass operation (99.9\%) compared with only $91.5 \%$ of patients at Ontario bariatric centres $(p<0.001)$.

\section{Health services use and mortality}

The proportion of patients who required at least 1 day of hospital services after out-of-country surgery was $51.8 \%$ compared with $50.4 \%$ among patients whose surgery was performed at an Ontario bariatric centre $(p=0.2)$ (Table 2). The mean number of days that this subset of patients required hospital services during the year after surgery was 5.1 days and 4.7 days, respectively (mean difference -0.5 days, $95 \%$ CI -0.1 to 1.1$)$. Patients requiring a stay in a critical

Table 2: One-year postoperative health services use and mortality among patients who received bariatric surgery out of country and those who received it at an Ontario Bariatric Network centre, 2007-2012

\begin{tabular}{|c|c|c|c|}
\hline \multirow[b]{2}{*}{ Outcome } & \multicolumn{2}{|c|}{ Group; no. (\%) or mean \pm SD } & \multirow[b]{2}{*}{ 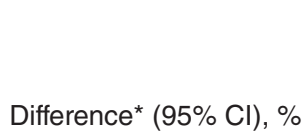 } \\
\hline & $\begin{array}{c}\text { Out of country } \\
n=4852\end{array}$ & $\begin{array}{c}\text { OBN } \\
n=5179\end{array}$ & \\
\hline Any use of hospital services $†$ & $2513(51.8)$ & $2610(50.4)$ & $-1.4(-3.3$ to 0.6$)$ \\
\hline No. of days hospital services used by patients requiring $\geq 1$ day & $5.1 \pm 12.4$ & $4.7 \pm 9.2$ & $-0.5(-0.1$ to 1.1$)$ \\
\hline Any emergency department visit & $2311(47.6)$ & $2409(46.5)$ & $-1.1(-3.1$ to 0.8$)$ \\
\hline No. of emergency department visits among patients with $\geq 1$ visit & $2.4 \pm 2.4$ & $2.3 \pm 2.2$ & $-0.1(-0.1$ to -0.3$)$ \\
\hline Any hospitalization & $832(17.2)$ & $1014(19.6)$ & $2.4(0.9$ to 4.0$)$ \\
\hline No. of days in hospital among patients requiring a hospital stay & $8.7 \pm 19.2$ & $6.5 \pm 12.5$ & $-2.2(-0.6$ to -3.7$)$ \\
\hline Any ICU stay & $66(1.4)$ & $119(2.3)$ & $0.9(0.4$ to 1.5$)$ \\
\hline No. of days in ICU among patients requiring an ICU stay & $10.6 \pm 12.3$ & $4.7 \pm 10.8$ & $-5.9(-2.3$ to -9.5$)$ \\
\hline Any ventilatory support & $29(0.6)$ & $52(0.5)$ & $-0.4(-0.8$ to -0.06$)$ \\
\hline No. of ventilated days among patients requiring ventilation & $11.1 \pm 12.1$ & $4.5 \pm 8.2$ & $-6.6(-1.5$ to -11.6$)$ \\
\hline Any physician assessment & $312(6.4)$ & $1761(34.0)$ & 27.6 (26.1 to 29.0$)$ \\
\hline No. of physician assessments among patients with $\geq 1$ assessment & $1.6 \pm 1.8$ & $1.2 \pm 0.6$ & $-0.4(-0.2$ to -0.6$)$ \\
\hline Reoperation & $49(1.01)$ & $197(3.8)$ & 2.8 (2.2 to 3.4$)$ \\
\hline No. of reoperations among patients with $\geq 1$ reoperation & $2.8 \pm 1.8$ & $1.4 \pm 0.7$ & $-1.4(-0.9$ to -1.9$)$ \\
\hline 30-d mortality & $4(0.1)$ & $7(0.1)$ & $0.05(-0.2$ to 0.08$)$ \\
\hline 1-yr mortality & $13(0.3)$ & $13(0.3)$ & $0.13(-0.2$ to 0.2$)$ \\
\hline
\end{tabular}


care unit stayed in the unit for a mean of 10.6 days if they were out-of-country recipients and 4.7 days if they were patients in the Ontario Bariatric Network (mean difference -5.9 days, $95 \% \mathrm{CI}-2.3$ to -9.5 ). The proportion of patients who had at least 1 physician assessment within the year after surgery was significantly lower in the group who had out-ofcountry surgery than in the Ontario Bariatric Network group (6.4\% v. $34.0 \%, p<0.001)$. There was no statistical difference in 30 -day mortality $(0.1 \%$ v. $0.1 \%, p=0.4)$ or 1 -year mortality $(0.3 \%$ v. $0.3 \%, p=0.9)$.

\begin{tabular}{|c|c|c|}
\hline Outcome & $\begin{array}{l}\text { Unadjusted rate } \\
\text { ratio }(95 \% \mathrm{Cl})\end{array}$ & $\begin{array}{c}\text { Adjusted* rate ratio } \\
(95 \% \mathrm{Cl})\end{array}$ \\
\hline Hospital services & $0.88(0.82$ to 0.95$)$ & $0.90(0.84$ to 0.97$)$ \\
\hline $\begin{array}{l}\text { Emergency } \\
\text { department visits }\end{array}$ & $0.92(0.86$ to 0.98$)$ & $0.98(0.92$ to 1.05$)$ \\
\hline Days in hospital & $0.86(0.73$ to 1.00$)$ & 0.88 (0.75 to 1.03$)$ \\
\hline Days in ICU & $0.74(0.45$ to 1.25$)$ & 0.78 (0.45 to 1.35$)$ \\
\hline Ventilatory support & $0.68(0.31$ to 1.49$)$ & 0.67 (0.27 to 1.65$)$ \\
\hline $\begin{array}{l}\text { Physician } \\
\text { assessments }\end{array}$ & 4.06 (3.66 to 4.50$)$ & 4.10 (3.69 to 4.56$)$ \\
\hline \multirow[t]{2}{*}{ Reoperations } & 1.86 (1.37 to 2.53$)$ & 1.84 (1.34 to 2.53$)$ \\
\hline & $\begin{array}{l}\text { Unadjusted OR } \\
\qquad(95 \% \mathrm{Cl})\end{array}$ & $\begin{array}{l}\text { Adjusted† OR } \\
\qquad(95 \% \mathrm{Cl})\end{array}$ \\
\hline 30-day mortality & $1.64(0.48$ to 5.61$)$ & $1.61(0.47$ to 5.54$)$ \\
\hline 1-year mortality & 0.93 (0.43 to 2.02$)$ & 0.87 (0.40 to 1.89$)$ \\
\hline \multicolumn{3}{|c|}{$\begin{array}{l}\text { Note: } \mathrm{Cl}=\text { confidence interval, ICU = intensive care unit, } \mathrm{OR}=\text { odds ratio. } \\
{ }^{*} \text { Adjusted variables included age, sex, procedure, rurality, income quintile and } \\
\text { comorbidity score. } \\
\text { †Adjusted variables included age and sex. }\end{array}$} \\
\hline
\end{tabular}

Table 4: Rate ratios comparing 1-year postoperative health services use among patients who received bariatric surgery in Ontario hospitals outside the Ontario Bariatric Network after versus before 2010

\begin{tabular}{|lc|}
\hline Outcome & Rate ratio* (95\% Cl) \\
\hline Hospital services & $1.07(0.59$ to 1.93$)$ \\
\hline Emergency department visits & $0.70(0.45$ to 1.07$)$ \\
\hline Days in hospital & $1.04(0.55$ to 1.99$)$ \\
\hline Days in ICU & $0.13(0.02$ to 1.14$)$ \\
\hline Ventilatory support & $0.13(0.01$ to 26.3$)$ \\
\hline Physician assessments & $4.74(2.36$ to 9.5$)$ \\
\hline Reoperations & $0.81(0.13$ to 5.00$)$ \\
\hline $\begin{array}{l}\text { Note: } \text { Cl = confidence interval, ICU = intensive care unit. } \\
\text { *Estimated using a negative binomial regression model adjusted for age, sex, } \\
\text { household income quintile in neighbourhood of residence, rurality, type of } \\
\text { bariatric surgery (gastric bypass v. other) and Johns Hopkins Adjusted Clinical } \\
\text { Groups comorbidity score. }\end{array}$ \\
\hline
\end{tabular}

After adjustment, surgery at a network centre was associated with a significantly lower rate of postoperative hospital services use than surgery out of country (rate ratio $0.90,95 \%$ CI 0.84 to 0.97$)$. This represented a $10 \%$ reduction in the mean number of days of hospital services (Table 3). No statistically significant differences were found with respect to time in critical care (rate ratio $0.78,95 \%$ CI 0.45 to 1.35 ) or time on ventilatory support (rate ratio $0.67,95 \%$ CI 0.27 to 1.65 ). The physician assessment rate (calculated among all patients, not just those requiring at least 1 assessment) was about 4 times higher among patients in the Ontario Bariatric Network group than among those who had surgery out of country (adjusted rate ratio 4.10, 95\% CI 3.69 to 4.56). The reoperation rate was also significantly higher in the Ontario Bariatric Network group (adjusted rate ratio 1.84 , 95\% CI 1.34 to 2.53). No difference was found with respect to 30-day or 1-year mortality after adjustment.

The subgroup analysis restricted to the 212 patients who had surgery in Ontario hospitals outside the Ontario Bariatric Network revealed no significant differences in use of postoperative health services before and after 2010 with the exception of the physician assessment rate (Table 4).

Table 5 presents the unadjusted and adjusted results of all covariates for the primary outcome.

\section{Table 5: Unadjusted and adjusted rate ratios comparing 1-year postoperative health services use among patients in the Ontario Bariatric Network group and those who received surgery out of country, by patient characteristic}

\begin{tabular}{|c|c|c|}
\hline Variable & $\begin{array}{c}\text { Unadjusted rate ratio } \\
(95 \% \mathrm{Cl})\end{array}$ & $\begin{array}{c}\text { Adjusted rate ratio } \\
(95 \% \mathrm{Cl})\end{array}$ \\
\hline $\begin{array}{l}\text { Surgery through the } \\
\text { Ontario Bariatric } \\
\text { Network }\end{array}$ & $0.88(0.82$ to 0.95$)$ & $0.90(0.84$ to 0.97$)$ \\
\hline Age & $1.00(0.99$ to 1.00$)$ & $1.00(0.99$ to 1.00$)$ \\
\hline Sex (male v. female) & 1.09 (0.99 to 1.19$)$ & $1.08(0.98$ to 1.19$)$ \\
\hline $\begin{array}{l}\text { Procedure (gastric } \\
\text { bypass v. other) }\end{array}$ & $0.88(0.74$ to 1.06$)$ & 0.95 (0.79 to 1.15$)$ \\
\hline Rurality (rural v. urban) & $1.17(1.07$ to 1.29$)$ & $1.26(1.14$ to 1.40$)$ \\
\hline \multicolumn{3}{|l|}{ ACG comorbidity score } \\
\hline$\leq 2$ & 1.00 (ref) & 1.00 (ref) \\
\hline 3 & $1.46(1.12$ to 1.89$)$ & 2.06 (1.53 to 2.76$)$ \\
\hline 4 & 2.29 (1.76 to 2.98$)$ & $3.29(2.44$ to 4.44$)$ \\
\hline 5 & 4.42 (3.35 to 5.83 ) & 5.67 (4.15 to 7.75$)$ \\
\hline \multicolumn{3}{|l|}{ Income quintile } \\
\hline 1 (lowest) & 1.00 (ref) & 1.00 (ref) \\
\hline 2 & 0.91 (0.82 to 1.00$)$ & $0.90(0.81$ to 1.00$)$ \\
\hline 3 & 0.90 (0.81 to 1.00$)$ & $0.90(0.81$ to 1.01$)$ \\
\hline 4 & 0.91 (0.81 to 1.01$)$ & 0.98 (0.88 to 1.10$)$ \\
\hline 5 (highest) & 0.81 (0.72 to 0.91$)$ & 0.79 (0.69 to 0.89$)$ \\
\hline
\end{tabular}




\section{Interpretation}

In this study involving 10031 patients, bariatric surgery at an Ontario Bariatric Network centre of excellence was associated with significantly less use of postoperative hospital services than out-of-country surgery. No difference was found with respect to postoperative mortality or time in critical care. However, the physician assessment and reoperation rates were higher in the Ontario Bariatric Network group. The increased use of outpatient physician services was probably due to the program's model of care.

There is limited literature evaluating the impact of bariatric centres of excellence with respect to use of postoperative health services. Previous studies have focused mainly on evaluating differences in clinical outcomes between bariatric centres of excellence and other hospitals. Accreditation of bariatric centres in the US is predicated primarily on hospital surgical volume and access to a dedicated multidisciplinary bariatric team. ${ }^{14}$ An evaluation of clinical outcomes 18 months before and after the US Centers for Medicare and Medicaid Services restricted bariatric surgery to centres of excellence in 2006 revealed the policy was associated with improved outcomes. ${ }^{15}$ Patients who underwent bariatric surgery after the policy decision had a significantly shorter hospital stay and a lower overall complication rate, but not significantly lower mortality. ${ }^{15} \mathrm{~A}$ recent study using administrative hospital data also showed that centre accreditation improves bariatric surgery outcomes. ${ }^{16}$ Other large population-based studies found no significant association between centre-of-excellence designation and clinical outcomes. ${ }^{17,18}$ Among US Medicare patients undergoing bariatric surgery, there was no significant difference in the rates of complications and reoperation between accredited and non-accredited hospitals. ${ }^{19}$

In our study, the comparison group was composed of patients who received surgery out of country rather than patients who received surgery in non-accredited hospitals, and thus the patients in our comparison group may have had difficulty finding local physicians to provide follow-up care. This lack of continuity of care was unique to our study population and could explain the higher use of hospital services in the group having out-of-country surgery. There are examples of other health services that have been outsourced to the US, such as treatment for substance abuse and radiation therapy. These programs have also been repatriated to Ontario primarily to save costs..$^{20,21}$

A major concern with medical tourism for bariatric surgery is the lack of continuity in care to monitor postoperative complications and nutritional deficiencies. The importance of follow-up care is further evidenced by the fact that bariatric surgery has long-term effects, with weight reduction and correlated changes in comorbidities continuing for months or even years after the procedure. ${ }^{22}$ Unlike other surgical procedures, the successful long-term treatment of morbid obesity and its comorbidities requires lifelong surgical, medical, psychological and dietary care. ${ }^{22}$ Dedicated bariatric programs based on best practices and clinical standards of care can ensure that patients consistently receive the safest and most effective care possible. ${ }^{23}$ As well, the opportunity to address concerns and complications in an outpatient setting can reduce the need for hospital services. Our findings support the American Society for Metabolic and Bariatric Surgery's position on global bariatric health care, which discourages "referral across international borders or long distances ... for patients requesting bariatric surgery if a high-quality bariatric program is available locally." ${ }^{24}$

\section{Limitations}

In our study, we relied on coded administrative health data and procedure codes, which are generally very reliable in Ontario. ${ }^{25,26}$ Although the validity of bariatric surgery codes has not been evaluated, the Ontario Schedule of Benefits includes specific fee codes for bariatric surgery. Our data sources did not include information on weight loss or resolution of comorbidities, and thus we could not comment on the effectiveness of surgery. Given our 6-year study duration, temporal factors improving surgical care over time, such as the wider application of laparoscopy, may have influenced health services use. The lack of a parallel bariatric control cohort outside Ontario after the program was implemented meant that it was not possible to completely isolate the effect of the Ontario Bariatric Network from temporal trends and perform an interrupted time-series analysis. To explore the potential of a secular bias, we did a subgroup analysis of inprovince centres outside of the network and found no difference in hospital services use before and after 2010 with the exception of physician assessments. The concern of immortal time bias in our study design is lessened by the fact that shorter follow-up time in Ontario because of longer stay in the US would favour less use of health services by the patients who received out-of-country surgery.

\section{Conclusion}

Our study showed that implementing a comprehensive and multidisciplinary provincial bariatric program provided a better model of care than outsourcing bariatric surgical services by increasing outpatient care and reducing the use of postoperative hospital services. Future research should include an economic evaluation to determine the costs and benefits of this policy decision.

\section{References}

1. Katzmarzyk PT, Mason C. Prevalence of class I, II and III obesity in Canada. CMA7 2006;174:156-7.

2. Bariatric surgery in Canada. Ottawa: Canadian Institute for Health Information; 2014.

3. Christou NV, Efthimiou E. Bariatric surgery waiting times in Canada. Can 7 Surg 2009;52:229-34.

4. Birch DW, Vu L, Karmali S, et al. Medical tourism in bariatric surgery. Am $\mathcal{f}$ Surg 2010;199:604-8.

5. Martin AR, Klemensberg J, Klein L, et al. Comparison of public and private bariatric surgery services in Canada. Can 7 Surg 2011;54:154-69.

6. Silva M. Mortality of morbidly obese patients on the waiting list for bariatric surgery [abstract]. Obes Surg 2006;16:401-2.

7. Health Quality Ontario. Bariatric surgery: an evidence-based analysis. Ont Health Technol Assess Ser 2005;5:1-148.

8. Ontario improves access to bariatric surgery: McGuinty government moving forward on diabetes strategy [press release]. Toronto: Ministry of Health and Long-Term Care; 2009 Feb. 23. 
9. Ontario Bariatric Network: Surgical program. Toronto: Ontario Bariatric Network; 2015. Available: www.ontariobariatricnetwork.ca/our-programs/surgical -program (accessed 2014 July 1).

10. Scales DC, Guan J, Martin CM, et al. Administrative data accurately identified intensive care unit admissions in Ontario. 7 Clin Epidemiol 2006;59:802-7.

11. Smith NS, Weiner JP. Applying population-based case mix adjustment in managed care: the Johns Hopkins Ambulatory Care Group system. Manag Care Q 1994:2:21-34.

12. Carlsson L, Börjesson U, Edgren L. Patient based 'burden-of-illness' in Swedish primary health care. Applying the Johns Hopkins ACG case-mix system in a retrospective study of electronic patient records. Int 7 Health Plann Manage 2002;17:269-82.

13. Woolston A, Tu YK, Gilthorpe M, et al. Measuring the impact of collinearity in epidemiological research. Int 7 Stat Probab 2013;2:1-11.

14. Hollenbeak CS, Rogers AM, Barrus B, et al. Surgical volume impacts bariatric surgery mortality: a case for centers of excellence. Surgery 2008; 144:736-43

15. Nguyen NT, Hohmann S, Slone J, et al. Improved bariatric surgery outcomes for Medicare beneficiaries after implementation of the medicare national coverage determination. Arch Surg 2010;145:72-8.

16. Morton JM, Garg T, Nguyen N. Does hospital accreditation impact bariatric surgery safety? Ann Surg 2014;260:504-8.

17. Livingston EH. Bariatric surgery outcomes at designated centers of excellence vs nondesignated programs. Arch Surg 2009;144:319-25.

18. Birkmeyer NJ, Dimich JB, Share D, et al.; Michigan Bariatric Surgery Collaborative. Hospital complication rates with bariatric surgery in Michigan. $7 A M A$ 2010;304:435-42.

19. Dimick JB, Nicholas LH, Ryan AM, et al. Bariatric surgery complications before vs after implementation of a national policy restricting coverage to centers of excellence. FAMA 2013;309:792-9.

20. Rush B, Tyas S, Martin G. Substance abuse treatment for Ontario residents in the United States. Addiction 1996;91:671-85.

21. McGowan T. Private management of a public service: What can be learned from the CROS experience? Hosp Q 2003;6:33-8.

22. Rynor B. Concerns raised about Ontario's new regime for bariatric surgery. CMA7 2010;182:E153-4.

23. Gould J, Ellsmere J, Fanelli R, et al. Panel report: best practices for the surgical treatment of obesity. Surg Endosc 2011;25:1730-40.
24. American Society for Metabolic and Bariatric Surgery Clinical Issues Committee. American Society for Metabolic and Bariatric Surgery position statement on global bariatric healthcare. Surg Obes Relat Dis 2011;7:669-71.

25. Williams JI, Young W. A summary of studies on the quality of health care administrative databases in Canada. In: Goel V, Williams JI, Anderson GM, et al., editors. Patterns of bealth care in Ontario. The ICES practice atlas. $2 \mathrm{nd}$ ed. Ottawa: Canadian Medical Association; 1996:339-45.

26. Juurlink D, Preyra C, Croxford R, et al. Canadian Institute for Health Information Discharge Abstract Database: a validation study. Toronto: Institute for Clinical Evaluative Sciences; 2006.

Affiliations: Department of Surgery (Elnahas, Jackson, Okrainec, Urbach), Department of Medicine (Bell) and Institute of Health Policy, Management and Evaluation (Elnahas, Austin, Bell, Urbach), University of Toronto; Institute for Clinical Evaluative Sciences (Austin, Urbach), Toronto, Ont.

Contributors: All authors contributed to the conception and design of the study. Ahmad Elnahas and David Urbach acquired the data. Ahmad Elnahas analyzed and interpreted the data, had full access to all of the data in the study and takes responsibility for the integrity of the data and the accuracy of the data analysis. Ahmad Elnahas, Timothy Jackson, Allan Okrainec, Peter Austin and David Urbach drafted the manuscript. All of the authors critically revised the manuscript for important intellectual content, approved the final version of the manuscript to be published and agreed to act as guarantors of the work.

Funding: This study used data from the Institute for Clinical Evaluative Sciences (ICES). The institute is funded by an annual grant from the Ministry of Health and Long-Term Care (MHLTC). The opinions, results and conclusions reported in this paper are those of the authors and not necessarily those of ICES and the MHLTC).

Supplemental information: For reviewer comments and the original submission of this manuscript, please see www.cmajopen.ca/content/4/3/ E489/suppl/DC1 